\title{
EFFECT OF EPINEPHRINE ON THE HUMAN HEART DURING METHOXYFLURANE ANAESTHESIA
}

\author{
André Jacques, M.D., F.r.C.P.(c), and Fernando Hudon, M.D., F.R.C.P.(c)
}

THE EFFECTS of epinephrine on the dog's heart during methoxyflurane anaesthesia have been reported. ${ }^{1,2}$ According to Bamforth, epinephrine can cause fibrillation of the dog's heart during deep anaesthesia at a potentiality about equal to that of chloroform, but much less than that of cyclopropane. On the other hand, Van Poznak found that arrhythmias produced by intravenous epinephrine in the conscious dog were lessened after anaesthesia with methoxyflurane.

In 30 human cases, epinephrine was injected subcutaneously in a dose of 0.001 to $0.002 \mathrm{mg} . / \mathrm{kg}$. in procaine 1 per cent to overcome oozing in the surgical field; one of the authors noted the absence of arrhythmias but, occasionally, the presence of a wandering pacemaker. ${ }^{3}$

It was decided to carry out an analysis of the effect on the human heart of epinephrine administered concomitantly with methoxyflurane inhalational anaesthesia, especially as it is becoming more and more apparent that in pharmacological procedures one cannot translate from dog to human, man being the final animal in the appraisal of new drugs. ${ }^{t}$

A series of 150 cases of submucous resections, rhinoplasties, mastoidectomies, tympanoplasties, cleft palate and hare-lip repairs was investigated. These surgical procedures had been performed under the following conditions:

Premedication. Meperidine-atropine in dosage according to age.

Anaesthetic. $\mathrm{N}_{2} \mathrm{O}-\mathrm{O}_{2}$-methoxyflurane with or without thiopentone induction. Orotracheal intubation with or without relaxants.

Vaporization of methoxyflurane. Heidbrink No. 8 ether vaporizer, Pentec, Boyle's ether vaporizer, Vernitrol ether vaporizer.

Monitoring equipment. Electrocardioscope, pulse monitor, transistor electrosphygmomanometer.

Pulmonary ventilation. This was assured proper throughout by means of the Bird No. 4 and No, 8 ventilators. It has been demonstrated that adequate ventilation, which assures reliable elimination of carbon dioxide and reliable oxygenation, will prevent most arrhythmias. ${ }^{5}$

None of the cases in this series had a medical history of thyrotoxicosis, phaeochromocytoma, tachycardia, or pulmonary dysfunction.

This investigation led to the discovery that epinephrine had often been used at random by the surgical staff as: ( $a$ ) A mixture of cocaine and epinephrine for topical analgesia ( 10 c.c. cocaine $10 \%$ with 3 drops of epinephrine $1 / 1,000$, 6 c.c. being used), even though it is known that the activity of the epinephrine may be increased as much as 240 per cent, ${ }^{6}$ or as much as 500 per cent or 600 per cent by cocaine. ${ }^{7}$ This technique has now been abandoned in otorhinolaryngology.

"Department of Anaesthesia, L'Hòtel-Dieu de Québec, Quebec 4. 
(b) Inadvertent subcutaneous injection of 1 c.c. of epinephrine $1 / 1,000$ in place of nalline during the course of one obstetrical delivery under $\mathrm{N}_{2} \mathrm{O}-\mathrm{O}_{2}$-methoxyflurane inhalational anaesthesia, which resulted in a transitory blood pressure elevation of $30 \mathrm{~mm}$. of $\mathrm{Hg}$, apnoea, slight tachycardia, and a cessation in the progress of labour. (c) For subcutaneous injection 6 drops of epinephrine 1/1,000 in 20 c.c. of isotonic saline solution. (d) For topical analgesia 3 drops of epinephrine $1 / 1,000$ in 10 c.c. of hexylcaine 5 per cent. (e) For subcutaneous injection lidocaine 2 per cent with epinephrine $1 / 50,000$.

This analysis showed that methoxyflurane, by itself, can initiate a nodal rhythm, a disappearance of $\mathrm{P}$ wave, and a wandering pacemaker. Concomitantly with $\mathrm{N}_{2} \mathrm{O}-\mathrm{O}_{2}-$ methoxyflurane inhalational anaesthesia, epinephrine in isotonic saline solution, in hexylcaine 5 per cent and in lidocaine 2 per cent caused a transient tachycardia (increase of 20 beats durirg 2 to 3 minutes), a blood pressure elevation of from 10 to $30 \mathrm{~mm}$. of $\mathrm{Hg}$ for 2 to 3 minutes. Cocaineepinephrine mixture momentarily initi tted a nodal rhythm, in addition to tachycardia and hypertension.

\section{SUMMARY}

This report is an analysis of 150 cases of $\mathrm{N}_{2} \mathrm{O}_{-} \mathrm{O}_{2}$-methoxyllurane inhalational anaesthesia with the concomitant topical and subcutaneous use of epinephrine added either to cocaine, hexylcaine, or lidocaine to overcome oozing in the surgical field. During the course of anaesthesia, the pulse, the blood pressure, and the cardiac rhythm were monitored with appropriate apparatus, and ventilation was adequately maintained with Bird ventilators No. 4 and No. 8.

The effects on the human heart and the circulation were transient, which might demonstrate that (1) methoxyflurane does not enhance the side-effects of epinephrine on the human heart and (2) that adequate ventilation of the lungs is a safe barrier to many anaesthetic complications.

\section{REFERENCES}

1. Bamforth, B. J.; Siebecker, K. L.; Kraemer, R.; \& Orth, O. S. Effect of Epinephrine on the Dog Heart during Methoxyflurane Anaesthesia. Anesthesiology 22: 169 (1961).

2. Van Poznak, A. \& Artusio, J. F., Jr. Series of Fluorinated Ethers. Fed. Proc. 19, Pt. 1: 273 (1960).

3. Hudon, Fernando. Methoxyllurane. Canad. Anaesth. Soc. J. 8: 544 (1961).

4. BEECHER, HENRY K. Trends in Anesthesia. J.A.M.A. 180: 43 (1962).

5. Matteo, Richard S.; Katz, Ronald L.; \& Papper, E. M. The Injection of Epinephrine during General Anesthesia. Anesthesiology 23,360 (1962).

6. Amror, L. Pharmacodynamie des anesthésiques locaux. Cours pour la préparation au certificat d'études spéciales d'anesthésiologie. Paris: Librairie Arnette (1954).

7. Marsir, D. F. Outline of Fundamental Pharmacology, p. 10. Springfield, Ill.: Charles C. Thomas (1951). 